\title{
A Nuclear Receptor-mediated Choleretic Action of Fibrates is Associated with Enhanced Canalicular Membrane Fluidity and Transporter Activity Mediating Bile Acid-independent Bile Secretion
}

\author{
Tomoji Nishioka ${ }^{1}$, Hideyuki Hyogo ${ }^{1}$, Yoshihiro Numata' ${ }^{1}$, Atsushi Yamaguchi', \\ Toshiya Kobuke ${ }^{1}$, Daisuke Komichi', Michihiro Nonaka1, Motoki Inoue ${ }^{1}$, \\ Yoshitaka Nabeshima', Mami Ogi ${ }^{1}$, Keiko Iwamoto', Tomokazu Ishitobi', \\ Takeyoshi Ajima, ${ }^{1}$ Kazuaki Chayama ${ }^{1}$, and Susumu Tazuma ${ }^{2}$ \\ ${ }^{1}$ Department of Medicine and Molecular Science, Graduate School of Biomedical Sciences, Hiroshima University, \\ ${ }^{2}$ Department of Genaral Medicine, Hiroshima University Hospital, Hiroshima, Japan.
}

\begin{abstract}
Fibrates are commonly used lipid-lowering agents that act via PPAR $\alpha$, a member of the nuclear hormone receptor superfamily. The mechanism(s) of fibrate-induced changes in the hepatic canalicular membrane and bile lipids are still unknown. Therefore, the aim of this study was to investigate the influence of fibrates on hepatic lipid metabolism and to assess the hepatocellular cytoprotective effect on hepatocyte canalicular membrane. Male ICR mice were fed standard chow with or without bezafibrate $(100 \mathrm{mg} / \mathrm{kg})$ for 6 days. The expression of canalicular membrane transporters (Mdr2 and Mrp2) was evaluated by RT-PCR and Western blotting. Canalicular membrane fluidity was also investigated. Canalicular membrane fluidity was markedly increased by fibrates. The expression of mdr 2 and mrp2 mRNA and protein showed a significant increase in fibrate-treated mice. These results suggested that fibrates improve liver function by enhancing bile secretion. The mechanism of the choleretic action of fibrate therapy might involve the enhancement of bile acid-independent bile secretion, since increased expression of Mdr2 and Mrp2 was found in fibrate-treated animals. These changes were very likely mediated by PPAR $\alpha$, and the increase of canalicular membrane fluidity may have been partly associated with enhancement of this transporter activity. J Atheroscler Thromb, 2005; 12: 211-217.
\end{abstract}

Key words: ABC transporter, Fibrate, Membrane fluidity, Steatohepatitis Abbreviations: ABC; ATP binding cassette, DPH; 1, 6-diphenyl-1,3,5-hexatriene, GAPDH; glyceraldehyde-3-phosphate dehydrogenase, PBC; primary biliary cirrhosis, PPAR; peroxisome proliferator-activated receptor

\section{Introduction}

Fibrates are widely used in the treatment of hyperlipidemia (1-3). These drugs decrease serum triglyceride lev-

Address for correspondence: Susumu Tazuma, Department of Genaral Medicine, Hiroshima University Hospital, 1-2-3, Kasumi, Minami-ku, Hiroshima 734-8551, Japan.

E-mail: stazuma@hiroshima-u.ac.jp

Received January 26, 2005

Accepted for publication April 12, 2005 els and increase HDL cholesterol levels in hyperlipidemic patients (1), as well as reducing the risk of coronary heart disease in patients with a low HDL cholesterol level (4).

Fibrates act via nuclear receptors known as peroxisome proliferator-activated receptors (PPARs), which belong to the nuclear hormone receptor gene superfamily. After heterodimerization with the retinoid $X$ receptor ( $R X R)$, PPARs alter the transcription of specific genes controlling lipoprotein metabolism by binding to a distinct response element, which consists of a direct repeat of the 
AGGTCA consensus sequence separated by 1 or 2 nucleotides (DR-1, DR-2) $(2,5)$. Three different types of PPARs have been identified, which are termed $\alpha, \delta$ (or $\beta$ ), and $\gamma$; each is encoded by a separate gene and shows a distinct pattern of distribution (5). PPAR $\alpha$ shows a high level of expression in the liver, and controls the expression of genes involved in the $\beta$-oxidation of fatty acids as well as genes encoding apolipoprotein A-I, A-II, and C-III (6).

Fibrate therapy has an adverse influence on biliary lipid composition and decreases the excretion of bile acids, leading to the supersaturation of bile acids in gallbladder bile and a consequent increase in the incidence of cholesterol gallstones among patients on long-term therapy $(7,8)$.

Recently, it has been reported that fibrates are effective for the treatment of cholestatic diseases such as primary biliary cirrhosis (PBC) (9-11). Several lines of evidence indicate that fibrates have beneficial effects in PBC patients, but their mechanism of action is not known.

The formation of bile critically depends on the active secretion of osmotically active compounds from the liver into the bile canalicular lumen. Several transporter proteins at the hepatocyte canalicular membrane are involved in the secretion of biliary constituents in an active, ATP-dependent manner. We speculated that the administration of a fibrate influences hepatocyte membrane activity and bile composition.

The aim of this study was to investigate the effects of fibrates on heparocytes, membrane fluidity and phospholipids (Mdr2), and organic anion (Mrp2) transporter activity. We demonstrated that the administration of fibrate led to changes in canalicular membrane fluidity and increased the activity of both transporters. This choleretic action of fibrate therapy might involve the enhancement of bile acid-independent bile secretion, since increased expression of Mdr2 and Mrp2 has been found in fibrate-administered animals. These effects are very likely mediated by PPAR $\alpha$, and the increase in canalicular membrane fluidity may be partly associated with enhanced transporter activity.

\section{Materials and Methods}

\section{Materials}

Bezafibrate was kindly provided by Kissei Pharmaceuticals (Tokyo, Japan). 1,6-diphenyl-1,3,5-hexatriene (DPH) was purchased from Molecular Probes (Oregon, USA). The materials for sodium dodecyl sulfate-polyacrylamide gel electrophoresis (SDS-PAGE) and a Western blotting kit were obtained from Bio-Rad Laboratories (Japan). Mouse anti-P-glycoprotein, MDR3 monoclonal antibody was purchased from Chemicon International, Inc (Temecula, CA). K4 antibody to detect Mrp2 was kindly provided by Dr. M. Muller (The Netherlands).

\section{Animals}

Male ICR mice weighing 25-30 g were obtained from Hiroshima Jikken Doubutsu (Hiroshima, Japan). All animals were kept in an environmentally controlled facility with a diurnal light cycle. Food was provided ad libitum and the animals had free access to water. The experimental protocol was approved by the Ethics Committee for Animal Experiments (Faculty of Medical Sciences, Hiroshima University).

\section{Experimental design}

All of the mice $(n=10)$ were fed standard chow for a 4week run-in period. Then the animals were randomly assigned to be fed either a control diet or the same diet containing bezafibrate $(100 \mathrm{mg} / \mathrm{kg}$ body weight dissolved in dimethyl sulfoxide (DMSO)) by a gastric tube for 6 days. The control group was given DMSO alone via the same technique. After the completion of treatment, mice were anesthetized with an intraperitoneal injection of Hypnorm (fentanyl/fluanisone) and diazepam. After the animals were sacrificed, their livers were excised, weighed, cut into small pieces, snap-frozen in liquid nitrogen, and stored at $-80^{\circ} \mathrm{C}$ until further analysis.

\section{Analytical Procedures}

\section{Isolation of liver plasma membranes}

Liver plasma membranes were isolated by density gradient ultracentrifugation as described elsewhere (12). Aliquots of the membranes were frozen in $10 \mathrm{mmol} / \mathrm{l}$ TrisHCL (pH 7.4) and $250 \mathrm{mM}$ sucrose supplemented with complete protease inhibitor cocktail (Roche, Mannheim, Germany) and stored prior to use at $-80^{\circ} \mathrm{C}$. Protein concentrations were determined according to the method of Lowry et al. (13) using bovine serum albumin as the standard. Enrichment of $\mathrm{Na}^{+} / \mathrm{K}^{+}$-ATPase (a marker enzyme for the canalicular fraction) was assessed as the specific activity of the enzyme in the isolated plasma membranes divided by the activity in the homogenate, and this parameter was used to determine the purity of the isolated membranes.

\section{Membrane fluidity}

Membrane fluidity was estimated by the DPH fluorescence depolarization method. In brief, $2 \times 10^{-3} \mathrm{M} \mathrm{DPH}$ in tetrahydrofuran was diluted 1,000 -fold with vigorous stirring for $10 \mathrm{~min}$ at $25^{\circ} \mathrm{C}$ to create a stable aqueous suspension of DPH $\left(2 \times 10^{-6} \mathrm{M}\right)$. Then a membrane suspension $(100 \mu \mathrm{g}$ protein $/ \mathrm{ml})$ was mixed with an equal volume of the DPH suspension and incubated at $37^{\circ} \mathrm{C}$ in the dark for $45 \mathrm{~min}$ (the time required to reach the maximum fluorescence intensity) with gentle shaking. Steady state fluorescence polarization measurements were performed using a Hitachi F2000 spectrofluorometer (Hitachi, Tokyo, Japan) equipped with a circulating water bath that 
was set at $37^{\circ} \mathrm{C}$. The excitation and emission wavelengths were 360 and $430 \mathrm{~nm}$, respectively. Polarization $(P)$ values were corrected for light scatter according to the method of Lentz et al. (14). The polarization value of DPH fluorescence was used as a measure of membrane fluidity because increased anisotropy indicates a decrease of phospholipid acyl chain motion within the membrane (15). All determinations were performed in triplicate.

\section{Western blot analysis}

Canalicular membrane proteins $(50 \mu \mathrm{g})$ were separated by sodium dodecyl sulfate-polyacrylamide gel electrophoresis, and transferred to nitrocellulose membranes (Millipore, Bedford, MA, USA) using a tank-blotting system according to the manufacturer's instructions (BioRad Laboratories, Hercules, CA). After the transfer, the membranes were blocked for $2 \mathrm{~h}$ at room temperature with $5 \%$ powdered skim milk dissolved in Tris-buffered saline containing $0.05 \%$ Tween 20 , and then incubated overnight at $4^{\circ} \mathrm{C}$ with the primary antibody. Immune complexes were detected using alkaline phosphatase-conjugated anti-rabbit IgG or rabbit anti-mouse $\lg G(1: 3,000)$ according to the manufacturer's instructions (Bio-Rad Laboratories). The detection of membrane transporters was achieved through comparison with the following standards: myosin (200 kDa), $\beta$-galactosidase (116 kDa), phosphorylase b (97 kDa), bovine serum albumin (66 kDa), and ovalbumin $(43 \mathrm{kDa})$. Then the immunoreactive bands on the membranes were quantified by densitometry.

\section{Analysis of mRNA using the reverse transcription polymerase chain reaction (RT-PCR)}

Total RNA was extracted from frozen mouse liver tissues using an RNeasy kit (Qiagen, Hilden, Germany) according to the manufacturer's instructions. RT-PCR was performed with a GeneAmp RNA PCR Core kit (Roche, Branchburg, $\mathrm{NJ}$ ) according to the manufacturer's directions. Single-stranded complementary DNA (cDNA) was synthesized from $2 \mu \mathrm{g}$ of total RNA using M-MuLV reverse transcriptase (Roche), and then subjected to PCR as described previously (16). Specific primer sets were designed for the various hepatic $A B C$ proteins. Using each primer set, an increasing number of PCR cycles was performed with other conditions being fixed in order to determine the optimal number of cycles. In every reaction, glyceraldehyde-3-phosphate dehydrogenase (GAPDH) was used as the internal control. Sequence analysis confirmed the specificity of the PCR primers for each product. In each experiment, water was used as a negative control. The PCR products (4- $\mu \mathrm{L}$ aliquots) were run on $2 \%$ agarose gels, which were stained with ethidium bromide.

\section{Statistical analysis}

Differences between the groups were determined by
ANOVA and the level of significance for all analyses was set at $p<0.05$.

\section{Results}

\section{DPH fluorescence polarization}

To determine whether the administration of bezafibrate had an influence on membrane fluidity, DPH fluorescence polarization was analyzed by spectrofluorometry. In fibrate-treated mice, the fluorescence polarization value was significantly low compared with that in control mice (fibrate-treated: $0.196 \pm 0.003$, control: $0.214 \pm 0.001, p$ $<0.01$ ), indicating that the fibrate caused an increase of canalicular membrane fluidity (Fig. 1). The mechanism of this beneficial effect on canalicular membrane fluidity might be closely associated with alterations of phospholipid and cholesterol metabolism that cause an increase in the cholesterol to phospholipid molar ratio of the hepatocyte membrane.

\section{Western blotting}

The expression of hepatic ATP-binding cassette (ABC) transport proteins (Mdr 2 and Mrp 2) during bezafibrate treatment was examined by immunoblotting. The changes of membrane transporter proteins were quantified by densitometry and expressed as a ratio relative to DPPIV, which is constitutionally expressed in the hepatocyte membrane. The expression of both Mdr2 and Mrp2 was significantly increased compared with that in vehicletreated mice (Fig. 2).

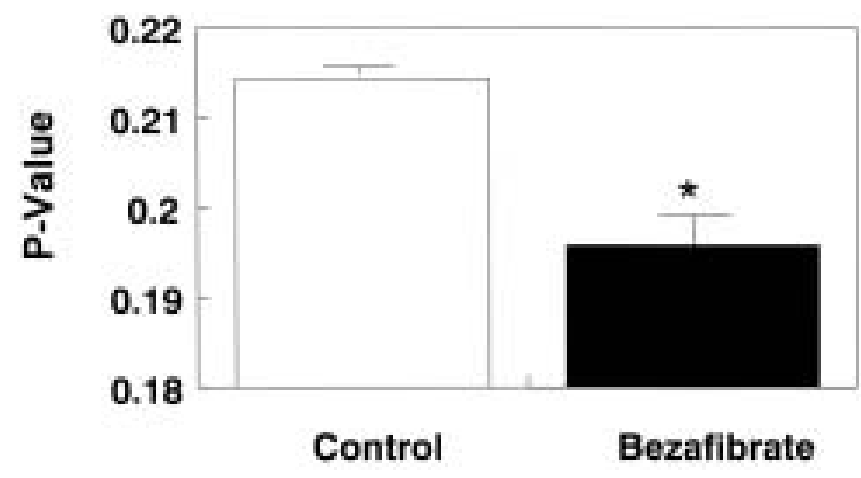

Fig. 1. Effects of fibrate on hepatocyte membrane fluidity. Plasma membranes were prepared from control mice $(n=4)$ and from bezafibrate-treated mice. Membrane fluidity was measured as 1,6-diphenyl-1,3,5-hexatriene (DPH) fluorescence polarization. In fibrate-treated mice, the fluorescence polarization value was significantly low compared with that in control mice (fibrate: $0.196 \pm 0.003$, control: $0.214 \pm 0.001, p<0.01$ ), indicating that the fibrate increased the canalicular membrane fluidity. $* p<0.05$ compared with controls. 

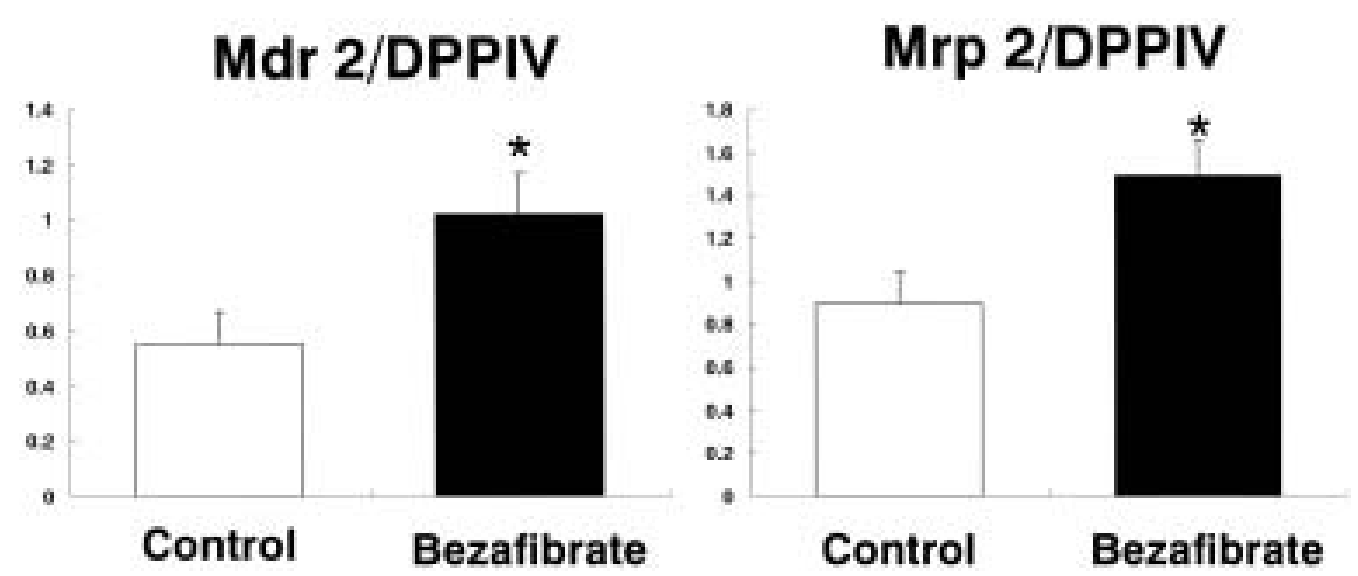

Fig. 2. Western blot analysis of mrp2 and mdr2 protein levels in liver plasma membrane fractions from untreated and bezafibrate-treated mice.

Hepatocyte membrane fractions were isolated from control mice $(n=4)$ and from bezafibrate-treated mice. The changes of membrane transporter proteins were quantified by densitometry and expressed as a ratio relative to DPPIV protein, which is constitutionally expressed in the hepatocyte membrane. Data (mean $\pm \mathrm{SD}$ ) are expressed as a percentage of the control bands intensigy. $* p<0.05$ compared with the control

\section{mRNA analysis by RT-PCR}

The relative mRNA levels of selected hepatic ABC transport proteins were analyzed by RT-PCR. As shown in Fig. 3, the steady-state level of Mrp2 mRNA was clearly higher in the livers of treated mice than in the livers of control mice and the Mdr2 mRNA level was also increased by fibrate treatment. These results were consistent with the changes in expression of these proteins on the canalicular membrane (Fig. 2) and were also closely associated with the membrane fluidity data (Fig. 1). In contrast, GAPDH levels were not influenced by fibrate treatment. The expression of PPAR $\alpha$ mRNA was significantly increased by the administration of its ligand, bezafibrate (Fig. 3).

\section{Discussion}

Fibrates are commonly used lipid-lowering agents that act via PPAR $\alpha$, a member of the nuclear hormone receptor superfamily. PPAR $\alpha$ shows high levels of expression in the liver and plays a pivotal role in lipoprotein metabolism.

Recently, Kurihara et al. has reported that the treatment of PBC with bezafibrate led to a sustained improvement in the levels of hepatobiliary enzymes and IgM during a relatively long period of monotherapy (10). We have speculated about the beneficial effects of fibrates with regard to the activation of PPAR $\alpha$. Because bezafibrate is a ligand with a strong affinity for PPAR $\alpha$, it may im-

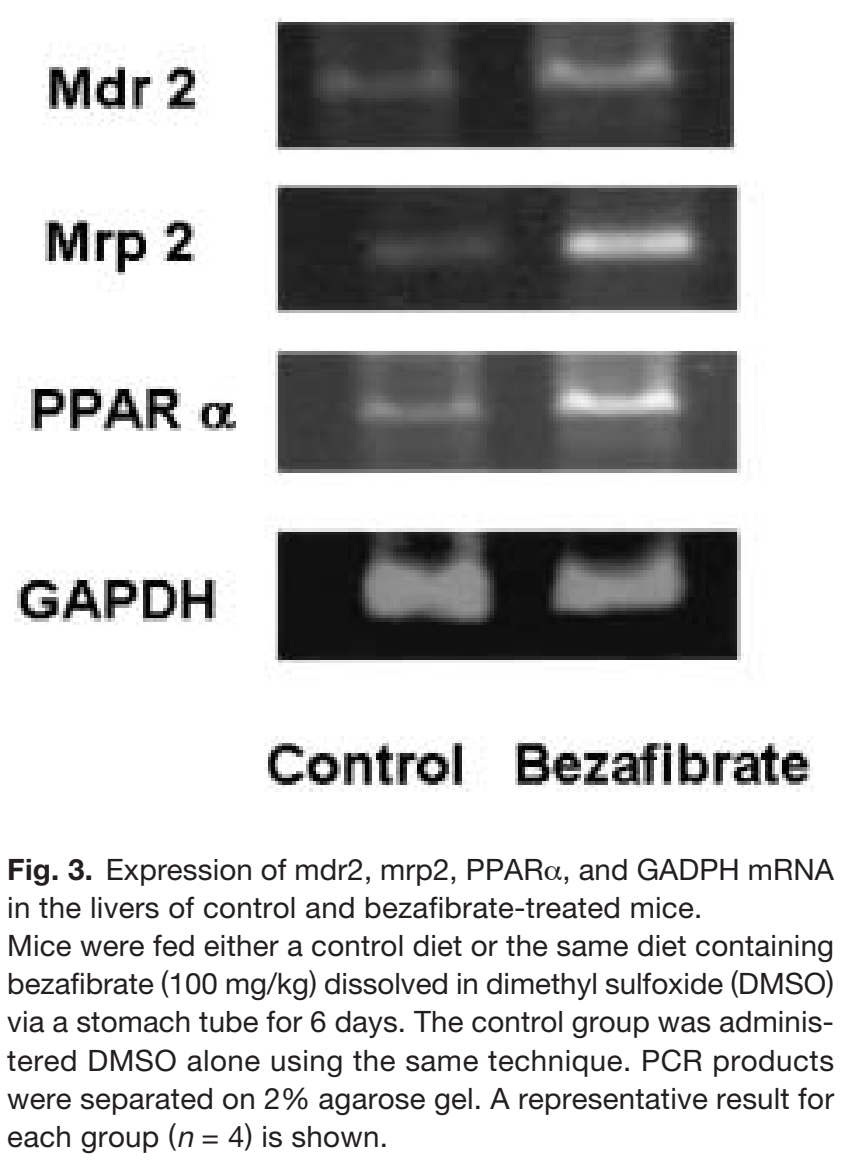


prove symptoms of PBC and steatohepatitis by eliciting several responses via PPAR $\alpha$. First, it causes the inactivation of leukotriene $B_{4}$ by activating the $\beta$ and $\omega$ oxidation of fatty acids (17). Second, it decreases the levels of interleukin- 6 and cyclo-oxygenase by suppressing the activation of nuclear factor $\kappa \mathrm{B}$, a transcription factor (18). Third, apolipoprotein A-II levels are increased via PPAR $\alpha$, suppressing the expression of intercellular adhesion molecule 1 and vascular cell adhesion molecule 1 (19). In addition, Inoue et al. have reported that bezafibrate had an antioxidative effect through activation of the PPAR $\alpha$ pathway in the liver $(20,21)$. They found that the administration of bezafibrate significantly reduced the level of plasma thiobarbituric acid-reactive substances and was closely associated with expression of the superoxide dismutase gene and PPAR $\alpha$ in the liver.

Furthermore, it is well known that fibrates affect biliary lipid excretion via PPAR $\alpha$ and lead to alterations of bile components. For example, fibrate treatment causes adverse changes in biliary lipid composition and decreases the excretion of bile acids, leading to the supersaturation of gallbladder bile and consequently to an increased incidence of cholesterol gallstones in patients on longterm therapy $(4,5)$. Post et al. have recently reported that fibrates inhibit bile acid synthesis via PPAR $\alpha$-mediated down-regulation of cholesterol $7 \alpha$-hydroxylase and sterol 27-hydroxylase, which may contribute to the formation of gallstones in patients on long-term therapy (22).

It has been reported that fibrates induce the expression of mdr2, which encodes the canalicular phospholipid translocator Mdr2 Pgp in rodents (23). Kok et al. recently investigated the physiological role of PPAR $\alpha$ using PPAR $\alpha$ null mice (24). They clearly demonstrated that the induction of Mdr2 mRNA and protein expression by fibrates is mediated by PPAR $\alpha$ (24). In this study, we confirmed that Mrp2 protein and mRNA expression were up-regulated in fibrate-treated mice as well as Mdr2 protein and mRNA expression. The enhancement of these proteins might be regulated by the PPAR $\alpha$ pathway. Production of Mdr2 protein in the canalicular membrane leads to the secretion of phospholipids into the bile and the formation of micelles with hydrophobic bile salts, thereby having a cytoprotective effect on biliary epithelial cells (25). Mrp2 expression is closely associated with bile acid-independent bile flow (BAIF), which is regulated by organic anions such as glutathione (26). Bile formation in the liver is driven by an osmotic gradient that is generated by the active secretion of relatively membraneimpermeable solutes into the canalicular lumen $(25,27)$. The Iminal accumulation of such osmotically active solutes promotes the movement of water and electrolytes through tight junctions and across the canalicular membrane. The active secretion of bile acids and their conjugates has been shown to account for 40-50\% of canalicular bile flow in all species examined (28). In this study, we demonstrated that expression of Mrp2 was significantly up-regulated in fibrate-treated mice. Enhancement of Mrp2 activity by over-expression might contribute to an increase of BAIF and thus lead to improved liver function. Kok et al. have reported that hepatobiliary bile salt flux was unaffected, but bile flow was strongly increased, in fibrate-treated mice and this latter effect was not seen in fibrate-treated PPAR $\alpha$ null mice. They concluded that the increased bile flow might be related to the PPAR $\alpha$ dependent excretion into bile of fibrate metabolites or other metabolities/solutes secondary to the activation of PPAR $\alpha$.

Another interesting finding was the alteration of hepatocyte membrane fluidity in fibrate-treated mice. To confirm these changes, we directly measured the membrane fluidity using fluorescence polarization. Fluidity was increased significantly after the administration of bezafibrate (Fig. 1), and this would represent a cytoprotective response to cholestasis. Taken together, these results indicate that changes to the membrane may confer on hepatocytes a resistance to increased intraductal pressure in the bile canaliculi and bile reflux. Moreover, these changes were tightly associated with the transporter activity of the canalicular membrane (Mdr2 and Mrp2). Several reports have suggested a connection between membrane lipid fluidity and membrane proteins (29-32). Simon et al. have reported that decreased sinusoidal membrane lipid fluidity was correlated with altered $\mathrm{Na}^{+}-\mathrm{K}^{+}$-ATPase activity in cholestasis induced by ethinyl estradiol (29), while Davis et al. demonstrated that this decrease of activity was reversed in vitro by addition of detergents that are known to increase membrane fluidity (32). Similar results correlating liver plasma membrane fluidity with membrane protein function have been reported by Storch and Schachter $(30,31)$. Taken together, these investigations indicate that the physiological function of membrane transporters might be influenced by membrane fluidity, which in turn is modulated by the fatty acid composition of phospholipids of the membrane lipid bilayer. We clearly demonstrated that the administration of a fibrate increased the membrane fluidity of hepatocytes and transporter activity.

The mechanism of the choleretic action of fibrate therapy might be enhancement of bile acid-independent bile secretion, since increased expression of Mdr2 and Mrp2 was found in fibrate-treated mice. These effects would probably be mediated by PPAR $\alpha$, and the increase of canalicular membrane fluidity may be partly associated with enhancement of transporter activity.

Acknowledgements: This study was been presented at the 53rd American Association for the Study of Liver Diseases, 1-5 November, Boston, MA, USA and has been published as an abstract (Hepatology, 2002, Vol 36 413A). This work was supported in part by a grant from the Japa- 
nese Ministry of Education, Culture, Sports, Science and Technology to Dr. Susumu Tazuma (No. 12670489).

\section{References}

(1) Watts GF and Dimmitt SB: Fibrates, dyslipoproteinaemia and cardiovascular disease. Curr Opin Lipidol, 10: 561-574, 1999

(2) Staels B, Dallongeville J, Auwerx J, Schoonjans K, Leitersdorf E, and Fruchart JC: Mechanism of action of fibrates on lipid and lipoprotein metabolism. Circulation, 98: 2088-2093, 1998

( 3 ) Pineda Torra I, Gervois P, and Staels B: Peroxisome proliferator-activated receptor alpha in metabolic disease, inflammation, atherosclerosis and aging. Curr Opin Lipidol, 10: 151-159, 1999

( 4 ) Rubins HB, Robins SJ, Collins D, Fye CL, Anderson JW, Elam MB, Faas FH, Linares E, Schaefer EJ, Schectman G, Wilt TJ, and Wittes J: Gemfibrozil for the secondary prevention of coronary heart disease in men with low levels of high-density lipoprotein cholesterol. Veterans Affairs High-Density Lipoprotein Cholesterol Intervention Trial Study Group. N Engl J Med, 341: 410-418, 1999

( 5 ) Schoonjans K, Staels B, and Auwerx J: Role of the peroxisome proliferator-activated receptor (PPAR) in mediating the effects of fibrates and fatty acids on gene expression. J Lipid Res, 37: 907-925, 1996

(6) Gervois P, Torra IP, Fruchart JC, and Staels B: Regulation of lipid and lipoprotein metabolism by PPAR activators. Clin Chem Lab Med, 38: 3-11, 2000

( 7 ) Einarsson K and Angelin B: Hyperlipoproteinemia, hypolipidemic treatment, and gallstone disease. Atheroscler Rev, 15: 67-97, 1986

( 8 ) Stahlberg D, Reihner E, Rudling M, Berglund L, Einarsson K, and Angelin B: Influence of bezafibrate on hepatic cholesterol metabolism in gallstone patients: reduced activity of cholesterol 7 alpha-hydroxylase. Hepatology, 21: 1025-1030, 1995

( 9 ) Kurihara T, Niimi A, Maeda A, Shigemoto $M$, and Yamashita K: Bezafibrate in the treatment of primary biliary cirrhosis: comparison with ursodeoxycholic acid. Am J Gastroenterol, 95: 2990-2992, 2000

(10) Kurihara T, Maeda A, Shigemoto M, Yamashita K, and Hashimoto E: Investigation into the efficacy of bezafibrate against primary biliary cirrhosis, with histological references from cases receiving long term monotherapy. Am J Gastroenterol 97: 212214, 2002

(11) Yano K, Kato H, Morita S, Takahara O, Ishibashi H, and Furukawa R: Is bezafibrate histologically effective for primary biliary cirrhosis? Am J Gastroenterol, 97: 1075-1077, 2002
(12) Yasumiba S, Tazuma S, Ochi H, Chayama K, and Kajiyama G: Cyclosporin A reduces canalicular membrane fluidity and regulates transporter function in rats. Biochem J, 354: 591-596, 2001

(13) Lowry $\mathrm{OH}$, Rosebrough AL, Farr AL, and Randal $\mathrm{RJ}$ : Protein measurement with the folin phenol reagent. J Biol Chem, 193: 265-275, 1951

(14) Lentz BR, Moore BM, and Barrow DA: Light-scattering effects in the measurement of membrane microviscosity with diphenylhexatriene. Biophys $\mathrm{J}$, 25: 489-494, 1979

(15) Kawato S, Kinoshita K, and Ikegami A: Dynamic structure of lipid bilayers studied by nanosecond fluorescence techniques. Biochemistry, 16: 23192324, 1977

(16) Hyogo H, Tazuma S, Nishioka T, Ochi H, Yamaguchi A, Numata Y, Kanno K, Sakomoto M, Asamoto Y, Tsuboi K, Nakai K, Yasumiba S, Sunami Y, and Kajiyama G: Phospholipid alterations in hepatocyte membranes and transporter protein changes in cholestatic rat model. Dig Dis Sci, 46: 2089-2097, 2001

(17) Devchand PR, Keller H, Peters JM, Vazquez M, Gonzalez FJ, and Wahli W: The PPARalphaleukotriene B4 pathway to inflammation control. Nature, 384: 39-43, 1996

(18) Staels B, Koenig W, Habib A, Merval R, Lebret M, Torra IP, Delerive P, Fadel A, Chinetti G, Fruchart $\mathrm{JC}$, Najib J, Maclouf $\mathrm{J}$, and Tedgui A: Activation of human aortic smooth-muscle cells is inhibited by PPARalpha but not by PPARgamma activators. Nature, 393: 790-793, 1998

(19) Calabresi L, Franceschini G, Sirtori CR, De Palma A, Saresella M, Ferrante P, and Taramelli D: Inhibition of VCAM-1 expression in endothelial cells by reconstituted high density lipoproteins. Biochem Biophys Res Commun, 238: 61-65, 1997

(20) Inoue I, Noji S, Awata T, Takahashi K, Nakajima T, Sonoda M, Komoda T, and Katayama S: Bezafibrate has an antioxidant effect: peroxisome proliferatoractivated receptor alpha is associated with $\mathrm{Cu} 2^{+}$, $\mathrm{Zn2}{ }^{+}$-superoxide dismutase in the liver. Life Sci, 63: 135-144, 1998

(21) Inoue I, Itoh F, Aoyagi S, Tazawa S, Kusama H, Akahane M, Matsunaga T, Hayashi K, Awata T, Komoda T, and Katayama S: Fibrate and statin synergistically increase the transcriptional activities of PPARalpha/RXRalpha and decrease the transactivation of NFkappaB. Biochem Biophys Res Commun, 290: 131-139, 2002

(22) Post SM, Duez H, Gervois PP, Staels B, Kuipers F, and Princen HM: Fibrates suppress bile acid synthesis via peroxisome proliferator-activated receptor-alpha-mediated downregulation of cholesterol 7alpha-hydroxylase and sterol 27-hydroxylase ex- 
pression. Arterioscler Thromb Vasc Biol, 21: 18401845,2001

(23) Chianale J, Vollrath V, Wielandt AM, Amigo L, Rigotti A, Nervi F, Gonzalez S, Andrade L, Pizarro M, and Accatino L: Fibrates induce mdr2 gene expression and biliary phospholipid secretion in the mouse. Biochem J, 314: 781-786, 1996

(24) Kok T, Bloks VW, Wolters H, Havinga R, Jansen PL, Staels B, and Kuipers F: Peroxisome proliferator-activated receptor alpha (PPARalpha)mediated regulation of Mdr2 expression and function in mice. Biochem J, 369: 539-547, 2003

(25) Nathanson MH and Boyer JL: Mechanisms and regulation of bile secretion. Hepatology, 14: 551566, 1991

(26) Ballatori N and Truong AT: Glutathione as a primary osmotic driving force in hepatic bile formation. Am J Physiol, 263: G617-G624, 1992

(27) Sperber I: Secretion of organic anions in the formation of urine and bile. Pharmacol Rev, 11: 109-134, 1959

(28) Boyer JL: Mechanism of bile secretion and hepatic transport. In: Andreoli TA, Hoffman JF, Fanestil DD, Schultz SG, editors. Physiology of Membrane Disorders, 2nd Edn, New York: Pleum, P. 609-636, 1986

(29) Simon FR, Fortune J, Iwahashi M, Gartung C, Wolkoff $A$, and Sutherland E: Ethinyl estradiol cholestasis involves alterlations in expression of liver sinusoidal transporters. Am J Physiol, 271: G1043G1052, 1996

(30) Storch J and Schachter D: A dietary regimen alters hepatocyte plasma membrane lipid fluidity and ameliorates ethinyl estradiol cholestasis in the rat. Biochim Biophys Acta, 798: 137-140, 1984

(31) Storch J and Schachter D: Dietary induction of acyl chain desaturases alters the lipid composition and fluidity of rat hepatocyte plasma membranes. Biochemistry, 23: 1165-1170, 1984

(32) Davis RA, Kern F, Showalter Jr R, Sutherland E, Sinensky M, and Simon FR: Alterations of hepatic $\mathrm{Na}^{+}, \mathrm{K}^{+}-$ATPase and bile flow by estrogen: effects on liver surface membrane lipid structure and function. Proc Natl Acad Sci USA, 75: 4130-4134, 1978 